\title{
A CRIATIVIDADE ARTÍSTICA KADIWÉU: ENTREVISTA COM BENILDA VERGÍLIO
}

FABIOLA IUVARO ${ }^{1}$

$U C D B / U F M S$

RESUMO: $O$ artigo tem como propósito entrelaçar diferentes visões sobre o tratamento da temática artística indígena na contemporaneidade, através do depoimento de Benilda Vergílio, indígena kadiwéu, graduada em Design pela Universidade Católica Dom Bosco. A análise tem como cenário as controvérsias antropológicas em torno das abordagens simbólicas que ao longo do tempo exerceram pleno domínio e subjugamento nos estudos sobre arte na ótica antropológica. Neste estudo, conduzido em forma de entrevista com a artista, é enfatizada a ação cognitiva da arte em contextos nativos, demonstrando que é necessário discutir a essência e o significado da arte indígena, sem deixar de lado o discurso do artista sobre eles.

PALAVRAS-CHAVE: Arte Indígena; ressignificação; ação cognitiva.

ABSTRACT: The article aims to interweave the different views on the contemporary Indian art through the testimony of Benilda Vergílio, Kadiwéu's Indian, graduated in Design at Dom Bosco Catholic University. The analysis it takes as backdrop the controversies surrounding the anthropological symbolic approaches that over time have had full control and subjugation in the study of art in the anthropological perspective. In this study, conducted by interview with the artist, it was emphasized the cognitive action of art in native context, showing that it is necessary to discuss the essence and meaning of indigenous art, without leaving aside their own speech.

KEYWORD: Indigenous art; reframing; cognitive action.

\footnotetext{
${ }^{1}$ Pós - Graduação em Antropologia Social, University of Victoria (Ano Acadêmico Projeto- Erasmus) Manchester/ Inglaterra - UK. Mestrado em Antropologia, Università degli Studi di Perugia Facoltà di Lettere e Filosofia - Perugia/ Itália - IT. Graduação em Antropologia e Arqueologia pela Universidade degli Studi di Perugia, Università di Lettere e Filosofia - Perugia/ Itália - IT. Mestranda em Desenvolvimento Local, Universidade Católica Dom Bosco (UCDB) - Campo Grande/MS. Integrante do grupo de pesquisa Antropologia, Direitos Humanos e Povos Tradicionais, Universidade Federal de Mato Grosso do Sul (UFMS). E-mail: fabiola.iuvaro@gmail.com.
}

Espaço Ameríndio, Porto Alegre, v. 6, n. 1, p. 69-96, jan.jun. 2012. 
FABIOLA IUVARO - A criatividade artística Kadiwéu...

\section{Introdução}

A aproximação com a artista Benilda Vergilio, indígena kadiwéu e acadêmica de Design na Universidade Católica Dom Bosco em Campo Grande, foi motivada pelo interesse de refletir sobre processos de reelaboração cultural em contextos urbanos e os conflitos vividos neles por sujeitos étnicos (PECHINCHA, 2008). Assim como a outros Kadiwéu, a história de Benilda se relaciona com a realidade de outras pessoas que se deslocam da comunidade para os centros urbanos.

A análise tem a intenção de produzir debates atuais à questão das novas gerações de artistas indígenas no Brasil, baseada e trilhada sob a perspectiva da artista kadiwéu Benilda Vergílio. Seu ponto de partida é um episódio em que ela é convidada a construir e decorar a casa de palha para o evento Vídeo Índio Brasil, em sua edição de 2010. Durante o evento, sediado em Campo Grande/MS, a artista foi convidada a participar e executar um trabalho final de sua própria autoria, realizando desenhos inspirados nos grafismos da etnia Kadiwéu, os quais representam também sua própria origem, com influência direta no processo criador de seus trabalhos artísticos.

O talento de criar roupas estampadas com a arte kadiwéu fez com que Benilda chamasse a atenção dos organizadores do Vídeo Índio Brasil, que a convidaram para decorar um artefato criado especialmente para o evento. Este protagonismo da artista foi a chave que resultou na análise da entrevista.

Parte das entrevistas ${ }^{2}$ ocorreu na residência e nos locais de trabalho da artista durante o evento cultural em 2010 a partir do consentimento livre e esclarecido de Benilda, dado quando solicitada a narrar sua vida. Desta narrativa será destacado o discurso da artista sobre o seu trabalho no papel de acadêmica e indígena.

Antes de examinar a fala da artista, é necessário esclarecer que este trabalho não constitui propriamente uma interpretação densa desta, o que exigiria conhecimento mais profundo do universo kadiwéu ou do trabalho das mulheres da etnia que moram na aldeia. Ele busca,

\footnotetext{
${ }^{2}$ Benilda Vergílio, artista kadiwéu, originada da aldeia Alves de Barros. As entrevistas com a artista Benilda Vergílio foram realizadas entre os dias 31 de julho e 07 de agosto de 2010, na cidade de Campo Grande - MS. Gravadas com câmera fotográfica cybershot compacta, formato AVI.
}

Espaço Ameríndio, Porto Alegre, v. 6, n. 1, p. 69-96, jan./jun. 2012. 
FABIOLA IUVARO - A criatividade artística Kadiwéu...

sobretudo, criar um exercício interpretativo e particular das palavras de Benilda sobre sua passagem pela Universidade. Trata-se de um exercício no sentido de apreender as manobras de identidade de um sujeito étnico e a representação de sua situação histórica no mundo (PECHINCHA, 2008).

Desde o princípio dos relatos de Benilda, se observa algumas lembranças de sua saída precoce da aldeia e também do início de sua experimentação artística. Ainda criança, a jovem foi estudar na pequena cidade de Bodoquena/MS e, posteriormente, foi transferida para a Escola Evangélica Lourenço Buckman, no distrito de AquidauanaTaunay/MS. Ali, teve contato com uma professora alemã e permaneceu por dois anos. Na ocasião, a professora despertou em Benilda a prazerosa sensação de receber elogios por seus trabalhos artísticos em sala de aula.

Sua história traça um eixo composto por determinados aspectos que demonstram os diversos locais por onde transitou, tanto fora da reserva indígena quanto no contexto urbano em que vive. Portanto, é preciso abrir novos diálogos sobre a questão da construção de uma teoria antropológica da arte - uma artista contemporânea e indígena simultaneamente traz consigo novas discussões ao mercado intelectual e artístico.

Em antropologia, autores como Pratt (1992) e Rama (2008) definem esses processos de 'transculturação'. No Ocidente, até pouco tempo, ela foi entendida hierarquicamente nas maneiras com que se reproduzia naturalmente um desequilíbrio do poder e da afirmação de um grupo para definir a história e a autenticidade do outro.

Por exemplo, os africanos que usaram o patrimônio cultural europeu eram vistos como imitadores que perderam suas tradições em um jogo com a soma "zero de aculturação" (COE, 1986). No entanto, os europeus que utilizaram o patrimônio cultural da África pareciam ser criativos, progressistas e modernistas (COE, 1986)

Em uma entrevista com Tamessir Dia, na Bienal de Veneza, McEvilley (1993) aponta como o artista nascido em Mali, que cresceu em Cote d'Ivoire, no continente africano, e posteriormente foi estudar na França, responde as perguntas sobre o que ele pensava de Picasso e outros pintores europeus. Ele diz que, na França, tomou o que era dele.

Espaço Ameríndio, Porto Alegre, v. 6, n. 1, p. 69-96, jan./jun. 2012. 
FABIOLA IUVARO - A criatividade artística Kadiwéu...

Picasso veio à sua casa e levou coisas, ou seja, inspirou-se na arte africana. Para ele, a tradição europeia foi uma forma de descobrir o valor da sua própria civilização. A Europa, após a Primeira Guerra Mundial, passava por uma crise de imaginação, de desenvolvimento no sentido artístico e cultural; assim, os europeus se voltaram para a África. McEvilly (1993) aponta que o artista não se inspira apenas na cultura africana, o que tornaria ridículo para qualquer africano falar hoje de negritude sem considerar as conexões históricas com o resto do mundo (MCEVILLY, 1993).

Por meio da perspectiva de vários artistas não ocidentais, indígenas, africanos, canadenses e brasileiros, sugere-se uma história mais complexa de apropriações e traduções artísticas.

\section{O encontro com a artista}

O primeiro encontro com Benilda aconteceu em uma Universidade, numa tarde calorosa de fevereiro, logo depois de meu regresso ao Brasil pela segunda vez, em dezembro de 2009. Benilda estava sentada na sala de estudos da Rede de Saberes, espaço dedicado aos acadêmicos indígenas na Universidade Católica Dom Bosco, em Campo Grande/MS.

Apresentei-me a ela e falei um pouco sobre minha recente chegada, origem e sobre o curso de mestrado no Brasil, além de lhe dizer também que não conhecia muitas pessoas por ali. Sentia-me à vontade naquela última sala do longo corredor de paredes brancas, com intenso cheiro de limpeza misturado ao aroma do café. Neste local surgiram as primeiras conversas com ela sobre sua arte e seu trabalho.

Ainda conhecendo a cidade e sua vida social, um certo dia me surpreendi com o convite de Benilda para que fôssemos conhecer a sua casa. E aproveitamos a ocasião para apreciarmos seus trabalhos, produzidos em diferentes eventos, ao longo de sua permanência em Campo Grande/MS.

Importa, neste ponto, frisarmos que não falamos de um mundo exótico e recém-descoberto, como foram as primeiras experiências empíricas antropológicas, ou algo parecido com o imaginário de Malinowski (1922). 
FABIOLA IUVARO - A criatividade artística Kadiwéu...

Dessa forma, a composição dos fatos que são abordados na entrevista sobre a vida da artista kadiwéu traça um novo caminho nos estudos sobre a arte indígena, no qual o que será discutido não poderá ser visto apenas como mais uma questão, à parte da vivência de vida acadêmica da artista durante o curso de Design na Universidade Católica Dom Bosco, na capital de Mato Grosso do Sul.

É preciso salientar que tanto as experiências cosmopolitas da artista quanto as peculiaridades enraizadas em sua cultura mais íntima confluem na expressão de sua arte kadiwéu.

Como Clifford James (1993) indica, a ideia não é apenas substituir o valor cultural da figura 'nativo' pelo termo intercultural 'viajante'. A experiência artística de Benilda Vergílio, ao contrário, centra-se nas interelações das duas figuras específicas - a indígena da comunidade e a estudante da cidade -, com seus conflitos particulares, históricos, de relação e de tensão entre ambas as influências vividas pela artista.

Percebe-se, no que refere especificamente à fala de Benilda, que esta mantém um relacionamento contínuo e recíproco com o universo de pessoas fora do mundo de sua aldeia sem deixar de haver forte e intensa conexão com a cultura indígena. $O$ que permanece claro, em todo momento, é uma complexa e enriquecedora relação vivida pela artista no contexto urbano.

Clifford James (1999) escreve sobre o confinamento e sobre a 'reclusão' das comunidades nativas indígenas. Por meio do processo de impostação representativa denominado congelamento metonímico, a Índia é equiparada com a hierarquia, a Melanésia com a troca, e pelo motivo de concernir as nossas reflexões, os nativos sul-americanos são vistos como - delimitados nos - e definidos dos - lugares aos quais pertencem, como grupos não contaminados pelo contato com o mundo. Nós sabemos que tais grupos, nestas classificações e termos, nunca existiram realmente.

Então, a pergunta para as nossas reflexões baseia-se no alcance do aspecto, da compreensão e do trabalho artístico de Benilda Vergílio, bem como de sua característica linguagem própria na contemporaneidade.

A análise conduzida em forma de entrevista, a partir de perguntas baseadas nos interesses da própria artista, não podia desconsiderar os 
FABIOLA IUVARO - A criatividade artística Kadiwéu...

trabalhos já dedicados aos estudos sobre a arte indígena, no âmbito nacional e internacional.

\section{As contribuições de Lévi-Strauss}

Muitas análises foram dedicadas às formas culturais dos povos indígenas. Gadamer (1975) evidencia como a analítica temporal da existência humana, desenvolvida por Heiddegger, mostra de maneira convincente que a compreensão não é, entre outros modos, comportamento dos sujeitos, mas o modo de ser da própria presença.

O que pretendemos discutir, antes da fala de Benilda Vergílio, são alguns pontos fundamentais sobre a criatividade artística tribal. Em Lost and Found Traditions: Native American Art, Ralph Coe (1986) destaca como autenticidade alguma coisa que é produzida, não sendo apenas salva. Coe efetivamente coloca em discussão o preconceito generalizado de que toda obra de honra tribal indígena está desaparecendo e lança dúvidas sobre os critérios convencionais para avaliar o grau de pureza e de 'autenticidade'.

Um longo capítulo sobre a tradição reforça este enunciado com inúmeras declarações feitas pelos vários artistas que são entrevistados por Coe (1986), jovens ou não, e que se mostram contra muitas definições ocidentais dominantes sobre a arte nativa. No texto, condensam-se longas descrições de artistas indígenas que propõem as próprias visões de mundo:

Os brancos pensam da nossa experiência como se pensa em alguma coisa passada. A nossa canção de verão repete apenas algumas palavras, mas sempre as mesmas. Aparentemente, estas palavras não significam nada em Inglês: os jovens líderes de pé. Estas são as palavras que expressam o nosso orgulho e alegria na luta contra o tempo e o esquecimento. "É uma canção de alegria. A tradição não é algo a dizer para qualquer pessoa. A sua essência está na sua ação" (COE, 1986, p.49).

Criatividade análoga é observada em muitas comunidades indígenas

brasileiras. Guardando as peculiaridades entre estas interpretações de

Espaço Ameríndio, Porto Alegre, v. 6, n. 1, p. 69-96, jan./jun. 2012. 
FABIOLA IUVARO - A criatividade artística Kadiwéu...

artistas indígenas da Nova Guiné, o que importa é a persistência e a produção da arte nos contextos indígenas em várias partes do mundo, considerando a completa complexidade dos cruzamentos entre os processos próprios de subjetivação indígena e ocidental. Contrariamente, há uma insistência muito forte, uma maneira específica de abordar as manifestações artísticas e estéticas indígenas.

Desde o trabalho de Boas e Mauss, Victor Turner e Geertz sabemos que, se desejamos entender o simbolismo da arte, precisamos entender a sociedade. Por isso, a arte envolve todo um sistema de signos compartilhados pelo grupo, que possibilita a comunicação (VIDAL E SILVA, 1992). Uma tradição antropológica inteira funde-se, então, na abordagem da arte como sistema simbólico, linguagem visual que deve ser apreendida através do entendimento da sociedade. Institui-se uma ideia que está presente, de modo geral, nas abordagens provenientes deste modelo: a relação primordial entre a arte e seu contexto específico de produção - a correlação direita entre um grafismo ou uma imagem, por exemplo, e a representação ou significação da ordem sociocultural de que faz parte.

Lévi-Strauss (1962) demonstra como, na 'civilização mecânica', o uso da função simbólica, por meio do 'pensamento periférico', emprega um mito individual, onde a cultura 'primitiva' recorre a um 'mito social'. Esta passagem se realizou pela transformação do status social do artista, ocorrida em consequência da dinâmica social europeia da Renascença (PANOFSKY, 1939). E não retringe-se, basicamente, à individualização do artista (LÉVI-STRAUSS, 1962), mas é, antes de tudo, a individualização da produção - criada por uma 'mito-poética' pessoal bem mais do que social, e destinada a uma clientela de classe para gozo estético exclusivo. Nesse sentido, o antropólogo francês (1955) aponta como a arte indígena kadiwéu, a pintura corporal, coloca-se a serviço da sociedade e de suas divisões.

Todavia, sem contradizer a ideia desta funcionalidade social da arte, o aprofundamento dela, conforme sugere, em seguida, LéviStrauss (1955), aproxima-nos ao outro nível, ou seja, a um 'sentido transcendental' através de uma 'vontade metassocial' - que, como o autor indica, faz da pintura corporal dos Kadiwéu algo tão tenaz, capaz 
FABIOLA IUVARO - A criatividade artística Kadiwéu...

de subsistir entre o abandono e o esquecimento de tantos de seus usos e de suas técnicas ao longo do tempo.

O primeiro a interessar-se da arte kadiwéu foi o missionário jesuíta Sanchez Labrador, em 1760; mas como relata Lévi-Strauss (1955), Boggiani (1975) foi o primeiro a descrever a pintura corporal kadiwéu. Aqui, é importante observar que durante os quarenta anos decorridos entre a visita de Boggiani e a do antropólogo francês, em 1935, o estilo, a técnica e a inspiração haviam se mantido imutáveis (LÉVI-STRAUSS, 1955).

Darcy Ribeiro (1980) dirá, mais tarde, como o relativo isolamento de que gozam os Kadiwéu na reserva e, sobretudo, a marcante personalidade cultural desse povo, seu orgulho ainda vivo, dá-lhes estímulo para continuar conduzindo muito do antigo patrimônio artístico (RIBEIRO, 1980).

Aliás, pode-se ler no trabalho de Lévi-Strauss (1955) a dificuldade em definir rígida teoria sobre uma analítica da obra de arte em contextos nativos. Dessa forma, o autor passa a dizer que aquilo que Ihe atribui significado é o aspecto da construção da arte.

Conhecemos o carácter extremamente enigmático da estrutura do tempo que se encontra a partir da festa. A repetição é constitutiva das festas, pelo menos das periódicas. É o que se chama retorno da festa. No entanto, aquela que retorna não é outra, nem a mera reminescência de algo festejado na sua origem. O carácter originalmente sacral de todas as festas exclui, evidentemente, essas distinções que conhecemos da nossa experiência do tempo como presente, recordação e expectativa. A experiência temporal da festa é, antes de tudo, a celebração sui generis presente. Assim a experiência da arte é uma forma de conhecimento sui generis, mas, mesmo assim, sempre significará conhecimento, ou seja, mediação da verdade (GADAMER, 1975).

Arte é conhecimento, e a experiência da obra de arte o torna partilhável. A festa só existe na medida em que é celebrada. Assistir significa participar. Na experiência da arte parece que a melhor maneira de caracterizar o seu modo de ser é através do conceito forjado no âmbito do sagrado, por meio do conceito de representation. A partir de todas essas ponderações, justifica-se caracterizar o modo de ser da arte 
FABIOLA IUVARO - A criatividade artística Kadiwéu...

através do conceito de representação. Gadamer (1975) aponta que a obra de arte deve ser entendida como um processo ontológico. No entanto, a experiência da arte que precisamos fixar contra a estética e a antropologia da arte tradicional relaciona-se com o modo de ser da obra de arte. Partindo da relação entre a arte - em geral - e a ideia de significado flutuante exposta por Lévi-Strauss (1965), podemos afirmar sem hesitação que é a síntese entre a noção de significado flutuante enquanto fonte da arte e as precisões sobre o modo de ser da obra de arte que traz reflexões estéticas sobre os trabalhos da artista indígena Benilda Vergílio, e que ao mesmo tempo aponta para a importância de aprofundar o processo de reconfirmar o potencial da arte: a vontade e a ação de produzir um objeto artístico.

\section{O papel da arte indígena no panorama brasileiro e internacional}

De outro modo, há estudos destas relações complexas no panorama brasileiro e internacional a respeito da arte indígena. Duas são as coletâneas de estudos sobre o tema de publicação recente (GELL, 1992; LAGROU, 2007;), nas quais se aborda a importância do discurso nativo sobre os grafismos indígenas e a abordagem icônica e indexical do grafismo, compreendendo a agência do desenho, segundo uma concepção da comunicação estética como sintética e simultânea.

Demarchi (2009) aponta que marca comum às abordagens é a preocupação de comprender a obra de arte - os desenhos, objetos e imagens - como referente complexo, que sintetiza, entrelaça e condensa elementos paradoxais e contraditórios e, por isso, age cognitivamente (LAGROU, 2007; GELL, 1992). Como aponta Lagrou (2007), a arte é eminentemente cognitiva, e as obras e as imagens não apenas representam nem somente significam, mas contrariamente tornam-se presentes (GELL, 1992).

O trabalho pretende abordar as formas artísticas próximas à linguagem, mas com tamanha capacidade de agência, de fazer relacionar pessoas, dimensões e seres kadiwéu, sem cair nas armadilhas de abordagens linguísticas ou simbólicas; refletir sobre como a arte comunica. Benilda disse durante uma das partes da entrevista como se 
FABIOLA IUVARO - A criatividade artística Kadiwéu...

aprende os desenhos de geração em geração. Olhando para sua avó fazendo arte. A artista aponta a maneira pela qual, a partir desta experiência, cada um começa a fazer sua arte.

Esta relação entre grafismo, linguagem, imagens e herança conduz a reflexão que permite compreender a arte como forma de comunicação não verbal, como a artista claramente diz, sendo o fazer artístico aquilo que relaciona as pessoas de sua família, privilegiando, dessa forma, a criatividade pessoal de cada indivíduo, mesmo tendo como referência os antigos grafismos da avó. Conforme sugere Lagrou:

O desenho é o caminho para o estar relacionado. Alude as relações, ligando mundos diferentes, e aponta para a interdepêndencia de diferentes tipos de pessoas. Nesta sua qualidade de veículo apontando para o estar relacionado é que reside sua capacidade de agir sobre o mundo [...] (LAGROU, 2007, p 66).

Lévi-Strauss (1955) sugere que os desenhos kadiwéu, recolhidos em 1935, apelavam para motivos relativamente simples, como espirais e cruzes gregas, mas estes são combinados de tal forma que cada obra possui um caráter original. Ele observa que em 400 desenhos reunidos não se pode observar dois semelhantes. Então, pretende-se, de agora em diante, refletir sobre a essência da arte. Investigar a peculiaridade da imagem, da pintura e do objeto artístico sem nos deixar desviar pela abstração exercida pela consciência estética (MERQUIOR, 1975). O uso de palavras como 'belo', quando se atenta para a forma linguística da sentença em que este ocorre, está muito mais sujeito a equívocos do que a maioria das outras palavras (WITTGENSTEIN, 1979). 'Belo' é um adjetivo pelo qual as pessoas intencionam dizer: "isto possui uma certa qualidade, a de ser belo" (WITTGENSTEIN, 1979, p28).

A maioria das pessoas tende a pensar que conceitos como beleza e as mesmas experiências do 'belo' sejam algo que podemos reconhecer automaticamente. Wittgenstein também sugere que, se perguntarmos a uma criança como ela aprende palavras, ‘belo' e 'lindo', por exemplo, verificaremos que aprendem tal qual interjeições. São de enorme importância, no ensino, os gestos e as expressões faciais exageradas. Estes, entre outros elementos, constituem expressões de 
FABIOLA IUVARO - A criatividade artística Kadiwéu...

aprovação. Não partimos de palavras, mas de ocasiões ou atividades para as quais damos significados.

Vocês poderiam pensar que a estética seja uma ciência a nos dizer o que é belo - o que é ridículo demais para ser expresso em palavras. Suponho que ela deveria também incluir que tipo de café tem bom gosto! (WITTGENSTEIN, 1979, p. 29).

\section{A liberação da questão simbólica a partir da experiência da arte}

O que importa na análise não é o problema do significado, mas a essência da imagem e do trabalho artístico da jovem artista Benilda Vergílio. Por essa razão, importa revisar os fenômenos da referência que convenciona a representação sagrada, como o símbolo. Importa também olhar o sentido especial da representação sugerida na obra de arte, para fixar o que the é comum e o que a distingue. Podemos dizer que a imagem é um processo de representação. Mas é necessário evitar confundir o sentido especial da representação sugerida na obra de arte com a representação sagrada, a exemplo do que se admite ao símbolo. Nem todas as formas de representação apresentam caráter de arte. Elas são também as insígnias, as quais possuem a estrutura de referência que as torna representações.

É importante para nossa análise apontar o que significa a representação na imagem como tal e a função da representação do símbolo. Símbolos e signos são tão poderosos que ditaduras querem impô-los. São tão perigosos que as democracias, cuja retórica é fundamentada na liberdade de opinião e de expressão, podem precisar regulamentar ou proibir sua exibição. $\mathrm{Na}$ maioria dos países democráticos, é crime queimar um pedaço de pano que represente a bandeira nacional. Mas os símbolos tanto armazenam significações, de acordo com Geertz (1997), quanto relacionam objetos, valores e seres. Os sentidos, no entanto, podem ser compartilhados e também competitivos.

Por exemplo, conforme comenta o antropólogo Marshall Sahlins (1997), existe uma grande diferença entre H2O e água benta, apesar de ambas serem a mesma substância química. Sendo assim, se 
FABIOLA IUVARO - A criatividade artística Kadiwéu...

transferimos sentimentos para as coisas, não será surpreendente que um gesto, um ato simbólico, possa ter tamanhas consequências. Também porque, em muitos casos, o sentimento que transferimos para signos e símbolos está ligado à esfera do sagrado.

Os símbolos, então, imprimem valores a fatos, às coisas ou às pessoas. Também os transformam e comunicam, relacionam, criam diferenças e possibilitam reconhecimentos. Precisamos conhecê-los, como precisamos conhecer um sinal, se quisermos seguir suas referências. Os símbolos são representantes e recebem sua função ontológica representativa daqueles que devem representar. A essa origem, no sentido funcional, chamamos de instituição. Assim, o que Ihe confere significado não é o seu próprio conteúdo ontológico, mas justamente sua instituição, investidura, consagração; ela dá significado ao que, em si mesmo, não tem; como o emblema nacional, a bandeira, os símbolos de um culto.

Neste caso, observamos que uma obra de arte não deve o seu significado genuíno a uma instituição, nem mesmo se tiver instituída de fato como imagem cúltica ou como monumento profano. O que the confere primeiramente seu significado não é o ato público da consagração ou da revelação, que o remete a sua destinação. Ao contrário, antes de receber uma função como memorial, ela já é uma configuração com função significativa própria, como representação que possui ou não imagem. Por exemplo, a instituição e a consagração de um monumento - não por acaso chamado de monumento arquitetônico, tanto os edifícios religiosos quanto os profanos -, quando a distância histórica que as consagrou, só realizam uma função que já estava envolvida no próprio conteúdo da obra (GADAMER, 1975).

Deste modo, a imagem encontra-se de fato a meio caminho entre o sinal e o símbolo. O seu representar não é um puro referir nem um fazer-se de outro. É justamente essa posição intermediária que the convém e a eleva a um status ontológico que é inteiramente seu. Agora podemos arriscar dizer que a essência da imagem encontra-se mais ou menos a meio caminho entre dois extremos. Esses extremos da representação são o puro referir - a essência do sinal - e o puro substituir - a essência do símbolo. 
FABIOLA IUVARO - A criatividade artística Kadiwéu...

De onde vem o poder particular daquelas coisas que chamamos arte? Os artistas parecem ter uma capacidade especial, quase mágica, de transformar simples objetos em algo transcendente. De onde vem esta capacidade?

Na perspectiva de autores como Lagrou (2007) e Gell (1992), entre outros, salvo as devidas proporções da profundidade ou não das abordagens da arte como sistema simbólico ou linguístico, o que se observa é a dificuldade dessa antropologia em elaborar uma teoria propriamente antropológica para a abordagem da arte (DEMARCHI, 2009). Pergunta-se: qual é a relação entre uma obra de arte e o seu ato comunicativo? O filósofo Deleuze (1983) responde a tal indagação: nenhuma. A obra de arte não é um instrumento de comunicação. Ela não contém, estritamente, a mínima informação, mas é a comunicação a título de resistência. Tomem o caso, por exemplo, do oxímoro que se opera no cinema - a disjunção entre voz sonora e a imagem visual: a imagem visual não tem nenhuma relação direta com a imagem sonora nessa arte.

A segunda pergunta, seguindo as palavras de Deleuze (1983), é: qual a relação misteriosa existente entre uma obra de arte e um ato de resistência, uma vez que os homens que resistem não têm nem o tempo nem talvez a cultura necessários para relacionar-se minimamente com a arte? Malraux (1992), numa declaração bem simples acerca da arte, afirma que ela é a única coisa que resiste à morte.

Retomando as palavras de Lévi-Strauss (1955), há um apontamento de uma força transcendental - 'uma vontade metassocial' que faz da pintura corporal dos Kadiwéu "alguma coisa tão tenaz", que até hoje é considerada uma das formas de expressão artísticas mais importantes deste povo -, não seria este um ato de resistência, a vontade de ação da arte como ato de resistência?

Por outro lado, deve-se conhecer o quadro histórico cultural para apreciar uma obra de arte e estar vinculado a um contexto artístico. Assim, para admirar e reconhecer uma obra-prima da literatura, por exemplo, deve-se conhecer a língua. Porém, de que forma seria possível, então, fazer o mesmo com uma obra de arte indígena com tal condição? Quem é responsável por essa tarefa? 
FABIOLA IUVARO - A criatividade artística Kadiwéu...

Lagrou (2007) defende que o papel do antropólogo da arte seria descobrir para onde apontam as intencionalidades artísticas: quais são as lógicas de ações, reações e relações sociais desencadeadas por, ou localizadas em, determinado objeto. Alfred Gell (1992) abre espaço para as discussões quando expõe sua opinião acerca da exposição ART/ARTIFACT - realizada em Nova York no ano de 1988, na qual a artista plástica, curadora e antropóloga Susan Vogel expôs uma rede de caça do Povo Zande (África) na entrada da exposição, provocando a reação do público, que não sabia ao certo se era uma instalação ou um mero artefato. Gell (1992), então, aproveita-se da discussão e polemiza com Arthur Danto (1986), defensor da ideia de que a rede Zande não é uma obra de arte, pois não permite "uma interpretação historicamente fundamentada", o que, para o filósofo da arte, diferenciaria a obra de arte do artefato.

Neste sentido, se, para a antropologia simbólica, a arte não só representa, mas significa, para as abordagens aqui colocadas (GELL, 1992; LAGROU, 2007), ela e suas imagens "presentificam"; no entanto, o que interessará no estudo da arte é a sua capacidade de ação cognitiva pela condensação de relações, identidades complexas, contraditórias e paradoxais (GELL, 1992; LAGROU, 2007).

\section{Entrevista com a artista}

Apesar da familiaridade construída entre a artista e eu devido aos frequentes encontros, a entrevista aconteceu de modo inesperado, depois de alguns dias da ocorrência da terceira edição do Vídeo Índio Brasil, em Campo Grande/MS, no ano de 2010.

$\mathrm{Na}$ pré-produção do evento, Benilda precisou ir diariamente ao local para fazer seus desenhos e deixá-los prontos para o dia da estreia. O espaço era uma casa de palha feita pelo Sr. Jurandir, da etnia Terena, que serviria como hall para os convidados e às coletivas de impressa do evento. A artista parecia não possuir evidência em relação à prática artística e, muitas vezes, passava despercebida diante da mídia. Esta falta de atenção repetiu-se diversas vezes, como oportunamente refere Benilda, sobretudo na noite de encerramento, quando todos os 
FABIOLA IUVARO - A criatividade artística Kadiwéu...

participantes e colaboradores, entre outros, foram agradecidos - a artista dos desenhos kadiwéu e o Sr. Jurandir, construtores da cabana de palha, foram esquecidos pelos jornalistas e repórteres. Na interpretação deste acontecimento, a artista relata alguns fatos semelhantes de sua infância e, mais recentemente, comenta que a arte indígena kadiwéu foi reconhecida como Arte Abstrata na Escola Nacional de Belas Artes no Rio de Janeiro, em ocasião do projeto Copyright, onde foram expostos 271 desenhos Kadiwéu.

Em 1997, um grupo de arquitetos latino-americanos na Alemanha foi procurado para realizar um projeto de renovação urbana do chamado "Bairro Amarelo", em Berlim-Hellersdorf. Um dos elementos marcantes para a reforma das fachadas deste local era o uso de grandes painéis de azulejos. Em Berlim, propõe-se o uso de arte indígena nos azulejos - sendo impossível o uso de padrões já conhecidos, foi estabelecido contato com a comunidade escolhida, os Kadiwéu, no Mato Grosso do Sul, conhecida pela riqueza de seus padrões geométricos contínuos.

Após pesar os prós e contras da proposta de participação no projeto, o conselho kadiwéu (Associação das Comunidades Indígenas da Reserva Kadiwéu - ACIRK) acabou realizando um concurso entre as mulheres da comunidade, no qual participaram mais de 90 artistas. Dos 271 desenhos resultantes, foram escolhidos seis para a execução nos azulejos na Alemanha.

Passado o complicado processo de formulação contratual, as artistas escolhidas receberam um honorário equivalente ao de artistas contemporâneos para tal tarefa. Os 50.000 azulejos produzidos na Alemanha com desenhos kadiwéu foram vinculados ao uso exclusivo do projeto do Bairro Amarelo. Tudo isso se tornou possível após o registro de Copyright dos 271 desenhos, feito na Escola Nacional de Belas Artes no Rio de Janeiro, conforme Benilda relata. Os desenhos foram reconhecidos como Arte Abstrata, já que, até então, a Arte Kadiwéu era encarada como puro artesanato. No registro de cada desenho consta o nome individual de cada artista, além do direito patrimonial coletivo da comunidade.

Este fato tão importante, afirma a artista, não foi levado adiante e caiu no esquecimento depois do projeto ser realizado. No entanto, não 
FABIOLA IUVARO - A criatividade artística Kadiwéu...

será esquecido em sua vida e na de muitas outras mulheres da comunidade kadiwéu. Sobre isso, ela assim se exprime:

Este projeto Copyright by Kadiwéu, criou uma intensa mobilidade na comunidade. O escopo era que as mulheres da comunidade desenhassem sobre um papel branco para que pudessem concorrer no concurso em 1997. Quando aconteceu o evento, eu ainda não havia me tornado universitária, por isso, lembro que participei indiretamente, acompanhando o entusiasmo da minha avó. O projeto previa que as mulheres cujos modelos fossem escolhidos na seleção teriam a possibilidade de ir a Berlim, para assistirem à inauguração do bairro amarelo, na Alemanha, como também visitar o Museu, onde tem muitos objetos kadiwéu.

Recordando a época, aprendi o quanto foi importante o sentido de colocar limites para o uso da nossa arte. Ainda eu era uma menina. Mas participei de todas as reuniões que foram realizadas, com a liderança indígena e a FUNAI, entre outras. Era preciso vencer o processo de formulação contratual (burocrático) junto com os empecilhos criados pela FUNAI. No entanto, foi possível enxergar um acordo. Ficava reconhecido, nos 271 desenhos, o valor artístico, concedido por uma Instituição reconhecida, como a Escola de Belas Artes no Rio de Janeiro. Aquela ideia de haver alto reconhecimento me orgulhou tanto. Este acontecimento, junto a outros, mudou o meu olhar sobre o nosso trabalho artístico (VERGÍlIO, entrevista em 2 de agosto de 2010).

Nesta perspectiva é que Benilda começa a entender, através de um significativo retrospecto dos fatos, a passagem entre seu presente e o evento de que participava. Como ela diz - "mundos separados" -, o mundo indígena assim permanece em relação aos outros; porém, em algum ponto se cruzam. A trajetória de vida da artista kadiwéu oferece um enredo muito rico, bastante complexo e condensador de uma experiência que, embora individual, é alegórica de uma experiência social, coletiva e histórica (PECHINCHA, 2008).

Mas o eixo da entrevista também sugere que é na sua experiência artística, no ato da sua criação, que a jovem consegue superar as disjunturas entre o seu ser indígena e o de cidadã brasileira. $O$ fato de ter detalhado o início do seu conflito, em sua experiência infantil,

Espaço Ameríndio, Porto Alegre, v. 6, n. 1, p. 69-96, jan./jun. 2012. 
FABIOLA IUVARO - A criatividade artística Kadiwéu...

alegoriza tanto a vulnerabilidade do lado atingido quanto a intensidade com que ela, como indígena, vivenciou aquela experiência.

O conflito, que não envolve apenas comunidade e indivíduo, mas ideologias rivais, pode, muitas vezes, desenvolver-se em inusitados tempos futuros. De criança, ela tinha dois mundos para comparar, e o referencial que encontrava no seu exacerbava a experiência de sofrimento que lhe causavam as interferências no mundo da escola muito rígida. O primeiro fato que Benilda narrou foi a austeridade que encontrou na Escola Evangélica Lourenço Buckman em Taunay, quando seus pais, depois que a artista passou por vários problemas na escola Joan Pedrossian em Bodoquena, decidiram mandá-la para lá:

Eu tinha contato direto com Bodoquena, por causa do meu avô, que vivia entre a aldeia e o município [...]. Assim, eu costumava ir com ele para a cidade. Também, na aldeia Alves de Barros, na minha época, tinha até a quarta série na Escola Emi Ejiwajegi; portanto eu precisava estudar em Bodoquena. Eu mesma, gostando de morar com meu avô, tive alguns problemas na Escola, por isso os meus pais decidiram me mandar para a Escola Evangélica em Taunay, onde passei dois anos. Eu precisava estudar. Deste modo, lá estava, sozinha. A maior parte das crianças da aldeia estudava na reserva, e depois em Bodoquena. Eu tinha que trabalhar em troca da oportunidade de estudar na escola evangélica em Taunay. Tinha que cozinhar, limpar os quartos e a cozinha, além de lavar roupas. Por isso, eu e as outras meninas passávamos o tempo estudando de manhã e limpando as instalações da escola durante a tarde. Dentro da casa havia muitas regras. Eu tinha que conviver com tudo isso. Muitas vezes, sentia-me como uma prisioneira, porque na aldeia não existem todas essas regras. Não gostava muito, mas depois encontrei uma professora alemã. Ela nos lecionava aulas de inglês, mas gostava muito dos meus trabalhos artísticos. Mesmo não me sentindo à vontade naquela escola, sentia certa familiaridade com aquela professora, que me incentivava a estimular os outros alunos para que criassem pinturas $e$ trabalhassem juntos. Sentia-me então muito à vontade em fazer desenhos. Era como se aquilo fosse tão natural que até esquecia o restante das coisas ao redor (VERGÍlIO, entrevista em 2 de agosto de 2010).

Espaço Ameríndio, Porto Alegre, v. 6, n. 1, p. 69-96, jan./jun. 2012. 
FABIOLA IUVARO - A criatividade artística Kadiwéu...

A comparação entre a rotina na escola e as suas atividades de pintura estrutura esta parte de sua fala. Em trecho seguinte da entrevista, Benilda enfatiza a importância percebida no seu encontro com a professora, o seu sentimento de familiaridade com ela, mesmo sentindo-se em um lugar estranho, apesar do tempo transcorrido na escola em Taunay. Interessante é focar alguns pontos chaves antes de prosseguir, como o sentimento de 'familiaridade' e do 'natural', que acompanham a narrativa. No entanto, fica mais difícil encontrar um sentimento contrário a estes, pois nem tudo o que é desconhecido nos dá a impressão de não ser familiar. Com isso, é preciso refletir sobre o que chamamos de desconhecido - a identificação por meio dos diálogos e encontros entre Benilda e a professora alemã, uma afinidade íntima que possuía na pintura e na arte um elo comum entre pessoas de culturas opostamente diferentes.

Quando eu era ainda pequena, fiquei muito fraca e triste por causa da morte da minha avó, que me havia criado. Eu não gostava de estar na sala de aula, somente de desenhar. Também percebo hoje que se dá pouca importância à matéria artística. Pensa-se que seja fácil ensinar esta matéria. Talvez por isso tenha passado a ser considerada uma matéria inútil, sobretudo por algum tempo, na maioria das escolas. As pessoas pensam que a cor de uma árvore é verde, a forma de uma flor deve ser de certa e única forma, que as folhas das árvores devem ser verdes e o céu azul, etc. Os professores, na maioria dos casos, não fazem com que os alunos aprendam a abrir os próprios olhos. Quando eu estava ainda no terceiro ano da escola, conheci uma professora alemã para quem a pintura significava uma paixão. Ela nos deixava pintar a céu aberto. No final da aula, tínhamos que lhe mostrar os esboços dos desenhos. Num certo dia, chovia e tivemos então que desenhar a paisagem que víamos pela janela da sala de aula. Da sala de aula poderíamos avistar um ginásio e um prédio público, mas também havia um bosque naquela mesma direção. Era um bosque de Ipê e Manga. Então, eu o desenhei. E [...] a professora me perguntou se era daquele modo que o via, realmente: Benilda, você vê isto realmente? Quando olhei novamente para meu desenho e o comparei com a imagem fora da janela, percebi que ambos eram completamente diferentes. Assim, eu havia desenhado o que imaginava e trazia na mente. Olhei bem e vi que

Espaço Ameríndio, Porto Alegre, v. 6, n. 1, p. 69-96, jan./jun. 2012. 
FABIOLA IUVARO - A criatividade artística Kadiwéu...

a árvore estava muito escura, e molhada pela chuva. A cor das folhas impregnadas de muitos verdes diferentes. Naquele momento, fiquei chocada e pensativa. Entendi então que o mundo era bem diferente. Foi a primeira vez que percebi que eu não via as coisas somente como pareciam ser! Daí em diante, passei a adorar a arte de desenhar (VERGÍlIO, entrevista em 2 de agosto de 2010).

A fala de Benilda passa a representar as referências de si e de sua comunidade. $\mathrm{O}$ encontro com aquela outra maneira de enxergar o seu ser indígena, sem precisar reprimir o seu tempo histórico, de brincar a céu aberto sem ter que submeter-se às regras rígidas do ensino e poder expressar o que pensava deixou uma marca muito importante na vivência da artista. Num dos trechos da próxima fala, surge claramente sua necessidade de criar novos vínculos com sua comunidade de referência, que é uma exigência também de posicionamento e de respeito pela sociedade na qual também está inserida - a brasileira.

Como base, o acesso à educação formal passa a ser um item importante da pauta de reivindicações indígenas, e o sentido desta conquista se vislumbra na fala da artista. A cultura indígena, através da dela, não se apresenta mais como uma tradição que precisa ser salva nem pode ser acusada de usar símbolos mortos, roubadas dos 'toucadores' de ontem, nem mesmo surge como símbolos de pedacinhos recolhidos lá e cá. É conjunto de códigos e artefatos, sempre sujeitos a novas combinações críticas e criativas. O seu posicionamento vai além da preocupação com a assimilação pelos indígenas. No entanto, demonstra como é possível manter autonomia perante a sociedade brasileira, um distanciamento, assim como outras incorporações julgadas necessárias.

Com certeza, hoje, crescemos num mundo bem diferente daquele dos meus avós, mas não acho que a habilidade de inovar e renovar o nosso sistema indígena seja uma indicação de falência. A coisa mais importante, que acho que muitos não índios ainda hoje continuam esquecendo, é o fato de que o sistema cultural local é ainda a estrutura dentro da qual nos definimos e categorizamos os objetos estrangeiros e os

Espaço Ameríndio, Porto Alegre, v. 6, n. 1, p. 69-96, jan./jun. 2012. 
FABIOLA IUVARO - A criatividade artística Kadiwéu...

modos de agir que nos foram apresentados (VERGÍLIO, entrevista em 5 de agosto de 2010).

Observa-se que invocar uma lógica cultural interna da comunidade como sendo aquilo que orquestra a mudança histórica não é o mesmo que falar de reprodução estereotipada do costume tradicional. A tradição consiste, aqui, em modos distintos que norteiam as mudanças: ela é necessariamente adaptada ao esquema cultural existente. Nesse sentido é que a arte de Benilda Vergílio vem adquirindo seu significado artístico.

Somos nós que damos nosso próprio sentido às coisas. Quando era criança, lembro que eu ficava olhando as mulheres kadiwéu nas produções das cerâmicas. Essa maestria que me fascinava era tanto uma questão de destreza representativa quanto de destreza técnica, ou seja, a nossa habilidade de dar sentido às coisas. Mas, ao mesmo tempo, não poderia aceitar a frustação de que essas mulheres enfrentavam uma sucessiva fase de desafio, que significava levar seus trabalhos para serem vendidos na cidade. Com pouca idade, já sentia o peso de um encontro entre os nossos objetos e os 'brancos da cidade' (Bodoquena). Essa ativividade era uma tentativa de receber um aproveitamento da nossa arte. Noções simplistas de 'aculturação' interpretaram estes fenômenos como uma consequência funcional e necessária do envolvimento da nossa comunidade na economia de mercado. Bem, eu acredito que hoje se faz necessário muito ceticismo sobre essas conclusões. Aqui, a maioria das coisas é acessível a todos. As pessoas sabem como fazer a maior parte daquilo que utilizam. Sendo assim, a maior parte das pessoas não indígenas ainda se perguntava como nós poderíamos lidar com os objetos ocidentais (VERGÍLIO, entrevista em 5 de agosto de 2010).

Benilda Vergílio vira e revira, em suas mãos, uma embalagem de tintas comprada numa loja de Campo Grande/MS, que agora utiliza para realizar alguns dos seus trabalhos artísticos na cidade, enquanto continua sua fala. As coisas, como as tintas, não têm apenas um único significado: as cores podem ser utilizadas em vestidos ou podem ser pintadas no corpo.

Espaço Ameríndio, Porto Alegre, v. 6, n. 1, p. 69-96, jan./jun. 2012. 
FABIOLA IUVARO - A criatividade artística Kadiwéu...

Lembrando novamente sua história e das mulheres de sua comunidade, que faziam objetos artísticos, ela continua a explicar sua arte:

\begin{abstract}
Quando criança, sabia do longo trabalho realizado pelas mulheres, em contraste com as poucas demandas de encomendas por parte dos consumidores brasileiros sobre os objetos indígenas. Junto, nutria uma tristeza de não conseguir entender esta situação, [...] me angustiava o sentimento provocado naquelas mulheres. Se penso no meu trabalho como artista, o que posso dizer é que os artistas usam as 'coisas' e assim produzem 'coisas', ou seja, criam uma forma. A tarefa do artista é ir além da matéria, tornar visível o invisível. É fazer da arte um objeto, que significa fazer, obter, conseguir, significar, etc. (VERGÍLIO, entrevista em 5 de agosto de 2010).
\end{abstract}

O conceito de forma (desenho, grafismo ou escultura) exposto pela artista, no trecho da fala anterior, designa a construção da configuração estética, não para promover algum tipo de significação de uma obra de arte, mas sim para responder a um estímulo impulsionado pela sensibilidade de criar o material. O chamado conteúdo objetivo não é, de forma alguma, uma matéria à espera de conformação posterior, mas, na obra de arte, este encontra-se sempre vinculado à unidade de forma e significado (MERQUIOR, 1975).

O problema para a análise é: o que significa compreender um desenho ou uma pintura artística indígena?

Kant (1993), em sua análise da lógica do conceito do símbolo, sugere que a representação simbólica não parece ser mera designação, pois esta observação não representa um conceito de maneira imediata, mas apenas um símbolo para a reflexão. Kant (1993) aplica o conceito de analogia principalmente para descrever a relação do belo com o bem ético, que não pode ser de subordinação nem de equiparação. "O belo é o símbolo do eticamente bom" (KANT, 1993, p. 34). Nessa fórmula prudente e pregnante, ele reúne a exigência de uma inteira liberdade de reflexão do juizo estético com o seu significado humano. Novamente, a fala de Benilda ajuda a fixar estes conceitos sobre forma, desenho e pintura:

Espaço Ameríndio, Porto Alegre, v. 6, n. 1, p. 69-96, jan./jun. 2012. 
FABIOLA IUVARO - A criatividade artística Kadiwéu...

A motivação é a lógica do meu fazer artístico. O motivo pelo qual um poeta [...] escreve é sua própria poesia. 0 exercício artístico é necessário. Percebi isso na Universidade. Há pouco tempo, precisei fazer um trabalho de cerâmica na Universidade. A minha agilidade com a técnica, na sala de aula, foi alguma coisa que me fez refletir. Apesar de não ter dedicado muito tempo a trabalhar com a cerâmica, o que vejo importar é o exercício artístico (VERGÍLIO, entrevista em 5 de agosto de 2010).

Benilda relaciona os motivos que levam às suas criações. As motivações podem ser tanto abstratas como objetivas; em todo o caso, sob o ponto de vista ontológico, elas são sempre imateriais. Mas isso não quer dizer que estejam destituídas do conteúdo. Antes, algo se transforma num motivo real por possuir uma unidade convincente e porque o artista deve impor essa unidade de um sentido, assim como aquele que a recebe e deve entendê-lo como unidade. Em outra parte da entrevista, ela afirma que a ideia é algo muito importante para os artistas:

As coisas são muito misteriosas. Eu acho que alguma coisa é a água ou ar, é uma xícara de chá, qualquer coisa que está em constante vibração. Tudo tem uma vibração sutil. Não há nada inerte no mundo. Apenas me parece que tudo possui a sua frequência. Há um artesão que fez essa xícara de chá, e eu estou lá, desenhando, assim como existe 'um escultor' com o seu trabalho. Não importa o que é melhor, o que importa é qual é a frequência do objeto. As coisas que os seres humanos não são capazes de produzir, por exemplo, são as coisas da natureza. Uma pedra que está ali, uma árvore, um fio que voa sem ser visto por ninguém, etc. Estas são criações da natureza. Todavia, devemos considerar que, quando produzimos algo, como uma xícara de chá, um prato, um copo d'água, uma colher, produzimos uma coisa útil para usar. Mas isso é útil até quando não venha se romper, porque depois ela perde a sua identidade e utilidade principal. Por exemplo, se eu deixar cair essa xícara de chá, quando estiver quebrada, não será mais uma xícara de chá.

Na minha visão, a arte é tentar criar outro tipo de natureza, que não seja algo tão natural assim, mas ao mesmo tempo o mais próximo possível da natureza. Isso não significa criar a natureza nem reproduzí-la.

Espaço Ameríndio, Porto Alegre, v. 6, n. 1, p. 69-96, jan./jun. 2012. 
FABIOLA IUVARO - A criatividade artística Kadiwéu...

Por exemplo, muitos poetas tradicionalmente tratam a lua como tema de sua poesia. Aqui não faz sentido criar uma lua nova. Nós certamente não podemos criar outra natureza, ao contrário, a arte é a mais próxima. Parece-me que a escultura é semelhante àquela rocha que fica lá imóvel, o que significa que embora caia em tantos pedaços, ainda continuará mantendo aquela vitalidade que Ihe é própria, assim a escultura, como a cerâmica, não se torna nunca uma xícara de chá (VERGÍlIO, entrevista em 2 de agosto de 2010).

As percepções de Benilda a guiam por um conjunto pessoal de concepções. Artista jovem que sofre e vive as contradições da nossa era moderna, mas que também revela a força de se impor na frente de um mercado artístico. Isso poderia ser visto como uma premonição de morte cultural? Devemos aceitar que a 'mercantilização' irá mais cedo ou mais tarde subverter todas as boas intenções tradicionais? Talvez. Mas acredito que não. Conforme observou Durkheim (2002), uma ciência do futuro não tem objeto. E como salientam Appadurai e Kopytoff (2008), o estatudo de mercadoria, nesse caso a 'mercantilizaçao' dos objetos artísticos, não é algo fixo, mas só um momento transitório na vida social de um objeto.

\section{Considerações finais}

Este artigo procura investigar as relações complexas entre o fazer artístico e o ser indígena. Podemos discutir sobre os possíveis significados de um quadro, uma pintura ou um desenho indígena? Em resposta, a fala da artista guia o texto através de sua visão sobre como poderia ser resolvido o enigma da comprensão e da interpretação da obra de arte. Gosto de um exemplo de Latour (2005), que nos apresenta um episódio dos colonialistas portugueses que encontram os negros indígenas na Guiné. Os católicos portugueses, 'modernos', chegaram cobertos com amuletos da Virgem e dos Santos, e quando viram os ídolos de pedra e madeira fabricados pelos guineenses, se chocaram com a má fé primitiva. Seria impossível para os portugueses construírem seus ídolos utilizando as mãos e, simultaneamente, acreditar que aqueles eram os verdadeiros deuses dos africanos. Devemos escolher a 
FABIOLA IUVARO - A criatividade artística Kadiwéu...

divindade real ou a artificial? Não é possível ser as duas, como pensam os guineenses? (LATOUR, 2005). Este exemplo revela-nos as relações que podem surgir entre o estado físico e a ideia de uma coisa.

A imagem, como foto, objeto artístico ou pintura, se transforma em um signo que merece interpretação. No Ocidente, cada época teve sua maneira de ver e ler as imagens da Virgem Maria e do Cristo, assim como teve sua maneira de estilizá-las. Essas 'leituras' nos dizem mais sobre a época considerada do que sobre os quadros. Uma palavra pode ter larguissímos números de acepções, mas suas ambivalências são identificáveis num dicionário, exaustivamente enumeradas: pode se chegar ao fim do enigma. Uma imagem é para sempre e definitivamente enigmática. Portanto, ela não tem percepção sem interpretação. Não há zero grau do olhar.

Os finos desenhos corporais realizados pelos Kadiwéu impressionaram pela riqueza de suas formas e detalhes, ao que temos fácil acesso através da vasta coleção recolhida por vários autores. Hoje os Kadiwéu mudaram? A arte de Benilda Vergílio é uma forma moderna de arte indígena? É para quem? Sob quais condições?

Em geral, o ser humano não vê o que não percebe. Para usar um exemplo próximo de nossa vida cotidiana - não perceberíamos uma simples xícara de chá ou uma colher se não tivéssemos a ideia do que esses objetos são na nossa mente. Cabe aqui uma anedota do Capitan Cook, a título de exemplificação: ele foi a uma ilha e encontrou indígenas, que lhe perguntaram de onde estava vindo. Os indígenas conheciam o mito de que chegaria um deus de pele branca do céu. $O$ chefe da tribo perguntou: "você vem do céu?". O Capitão apontou com as mãos a sua barca enorme. Mas os indígenas, que nunca haviam visto uma barca assim, mesmo olhando para ela, não conseguiram percebêla.

Durante milênios, as imagens, os produtos artísticos, levaram os homens a um sistema de correspondências simbólicas, ordem cósmica e ordem social, muito antes que a escrita linear viesse compor as sensações e as cabeças. Os vitrais, os baixos-relevos e a estatuárias transmitiram algo do cristianismo e da comunidade de literários que assim apreenderam os valores simbólicos do crucifixo ou do triângulo trinitário. Essas imagens não só transmitiam valores, mas também 
FABIOLA IUVARO - A criatividade artística Kadiwéu...

modelavam comportamentos e instauravam um estilo de existência. Exerceram uma ação sobre homens. Volto a perguntar: o que isto acrescenta quando queremos discutir o que pode significar compreender um desenho indígena?

Em consonância com Wittengstein (1979), podemos afirmar que a compreensão de uma frase de linguagem bem mais se parece com a compreensão de um tema musical do que com um desenho. No exemplo de uma obra de arte própria de linguagem, quando dominamos o idioma em que está escrito, ele poderá significar uma obra de arte para nós. Também a incompreensão pode estar relacionada com a teorização do que interpretamos como desconhecido. Benilda salienta:

As pessoas em geral estão longe da arte em suas vidas cotidianas e não têm a mínima ideia do que nós, artistas, fazemos. Um contexto maior para nós, indígenas, é que as pessoas pensam em nossa arte só como produção de objetos de uso diário, tais quais: vasos, pratos, colheres, etc. Objetos que não podem ser criativos, porque são iguais ao original, que são, na maioria dos casos, similares aos objetos utilizados em casa ou no dia a dia das pessoas. Quando comecei a estudar, vim para Campo Grande/MS e fiz o meu primeiro trabalho para um público, daí, a primeira coisa que muitas pessoas faziam era perguntar 0 que significava a minha arte. O que representava? Mas como eu poderia ter respondido? (VERGÍLIO, entrevista em 2 de agosto de 2010).

A situação pode ser comparada à dos indígenas de Capitan Cook. Benilda continua:

As pessoas podem viver tranquilamente sem perceber a arte na vida codidiana. $\mathrm{E}$ isto acontece o tempo todo similarmente à nossa arte da parte das pessoas. Quando comecei a trabalhar, apenas cheguei à cidade e compreendi que não queria viver e trabalhar olhando as duas culturas, a indígenas e a brasileira, como se fossem lados separados. A cultura em que me formei é indígena, por isso tenho orgulho de ser Kadiwéu, mas também sou brasileira. Eu sei que as duas culturas não podem se confundir/misturar. É fácil achar as diferenças entre ambas, mas muito mais difícil é achar as semelhanças. O meu trabalho começa no momento

Espaço Ameríndio, Porto Alegre, v. 6, n. 1, p. 69-96, jan./jun. 2012. 
FABIOLA IUVARO - A criatividade artística Kadiwéu...

em que quero achar coisas em comum entre elas. Isto é o início do meu trabalho criativo. Quando criança, olhava para as fotos bonitas dos pintores estrangeiros e via as pinturas da nossa cultura, os nossos objetos feitos com formidável maestria, comecei a pensar que devia conhecer melhor as artes indígenas. Viajar para achar os pintores, artesãos, os cantores e autores de todas as comunidades indígenas. Sinto-me indígena e nunca posso esquecer disto, mas também sou brasileira e artista, e o meu trabalho começa, assim, como uma pesquisa para buscar uma ponte entre as duas culturas (VERGÍlIO, entrevista em 2 de agosto de 2010).

O trabalho obriga-nos a pensar sobre o tema do valor. O que quero dizer com valor? Valor artístico, de mercado, político? Como diz Amartya Sen - "o valor, esse é o núcleo duro desses tempos, dessa mutação civilizatória que estamos vivendo, de modo diferente aqui, nessa parte de mundo, como em outras" (SEN, 2004, p. 10).

\section{Referências bibliográficas}

BOAS, Franz. Primitive Art. New York: Dover Publication, 1955.

BOGGIANI, Guido. Os Caduveos. Belo Horizonte: Itatiaia, 1975.

CLIFFORD, Geertz. O saber local: novos ensaios em antropologia interpretativa. Petropolis: Vozes, 1997.

CLIFFORD James. I frutti puri impazziscono. Torino: Bollati Boringheri, 1993.

. Strade: viaggio e traduzione alla fine del secolo XX. Torino: Bollati Boringhieri, 1999.

COE, Ralph. Lost and found traditions: native american art - 1965-1985. Seattle: University of Washington Press, 1986.

DANTO, Arthur. The philosophical disenfranchisement of art. New York: Columbia University Press, 1986.

DEMARCHI Andrea. Armadilhas, quimeras e caminhos: três abordagens da arte na antropologia contemporânea. Espaço Ameríndio, Porto Alegre, v. 3, n. 2, p. 177-199, 2009.

DELEUZE, Gilles. Cinema 1: a imagem-movimento. Paris: Minuit, 1983.

Espaço Ameríndio, Porto Alegre, v. 6, n. 1, p. 69-96, jan./jun. 2012. 
FABIOLA IUVARO - A criatividade artística Kadiwéu...

DURKHEIM, Emile. As regras do método sociológico. São Paulo: Ed. Martin Claret, 2002.

GADAMER, Hans Georg. Truth and method. London: Continuum Publishing Group, 1975.

GELL, Alfred. The technology of enchantment and the enchantment of technology. In: JEREMY, Coote; ANTHONY Shelton (Orgs.). Anthropology, art, and aesthetics. Oxford: Oxford University Press, 1992. p. 40-63.

HALL Stuart. Representation, cultural representations and signifying practices. London: Sage publications, 2003.

KANT, Immanuel. Crítica da faculdade do juízo. Rio de Janeiro: Forense Universitária, 1993.

KOPYTOFF, Igor, A biografia cultural das coisas: a mercantilização como processo. In: APPADURAI, Arjun (Org.). A vida social das coisas: as mercadorias sob uma perspectiva cultural. Niterói: EDUFF, 2008. p. 89-121.

LAGROU, Elsje M. A fluidez da forma: arte, alteridade e agência em uma sociedade amazônica. Rio de Janeiro: Topbooks, 2007.

LATOUR, Bruno. Il culto moderno dei fatticci. Roma: Meltemi, 2005.

LÉVI-STRAUSS, Claude. Tristes Tropiques. Paris: Plon,1955.

Le totemisme aujourd'hui. Paris: P.U.F., 1962.

Introduzione all'opera di Marcel Mauss. In: MAUSS, Marcel. Teoria generale della magia e altri saggi. Torino: Einaudi, 1965. p. 9-55.

MALINOWSKI, Bronislaw. Argonauts of the Western Pacific. New York: Dutton, 1922.

MCEVILLEY, Thomas. Fusion: West African artists at the Venice Biennale. New York: Museum for African Art, 1993.

MERQUIOR, José Guilherme. A estética de Lévi-Strauss. Rio de Janeiro: Edições tempo brasileiro Ltda, 1975.

MALRAUX, André. The Conquerors. Chigado: University of Chicago Press, 1992.

PRATT, Mary Louise. Imperial Eyes: Travel Writing and Transculturation. London: Routledge, 1992. 
FABIOLA IUVARO - A criatividade artística Kadiwéu...

PANOFSKY, Erwin. Studies in Iconology: humanistic themes in the Art of the Renaissance. New York: Oxford University Press, 1939.

PECHINCHA, Mônica T.S. A proteção da cultura ao sujeito transeunte: uma entrevista com Jorge Terena. Tellus, Campo Grande, v. 8, n. 14, p. 61-86, 2008.

PRICE, Sally. L'Esthetique et les temps: commentarie sur l'histoire orale de l'art. L'Ethnografie, Paris, v. 8, p. 215-225, 1986.

RAMA, Ángel. Transculturación narrativa en América Latina. Buenos Aires: Edições El Andariego, 2008.

RIBEIRO, Darcy. Kadiwéu: ensaios etnológicos sobre o saber, o azar e a beleza. Petrópolis: Vozes, 1980.

SALHINS, Marshall. How Native think: about Captain Cook. Chicago: The University of Chicago Press, 1993.

SALHINS, Marshall. O "pessimismo sentimental" e a experiência etnográfica: por que a cultura não é um "objeto" em via de extinção (parte I). Mana, Rio de Janeiro, v. 3, n. 1, p. 41-73, 1997.

SEN, Amartya. How does culture matter? In: RAO,Vijayendra; Walton M Michael (Orgs.). Culture in public acton. California: Standford University Press, 2004.

WITTGENSTEIN, Ludwig. Wittgenstein: as investigações filosóficas, 1889-1951. São Paulo: Abril Cultural, 1979.

VIDAL, Lux; SILVA, Aracy. Antropologia estética: enfoques teóricos e contribuições metodológicas. In: VIDAL, Lux (Org.). Grafismo indígena. São Paulo: Studio Nobel/Fapesp/Edusp, 1992.

Espaço Ameríndio, Porto Alegre, v. 6, n. 1, p. 69-96, jan./jun. 2012. 